\title{
Factors Underlying Attitude towards Agriculture as Predictors of Willingness to Enrol in the Subject by Senior Secondary Students in Botswana
}

\author{
S. P. Baliyan \\ Email: spbaliyan@yahoo.com \\ H. J. Nenty \\ Department of Educational Foundations, Faculty of Education, University of Botswana, Gaborone, Botswana \\ Email: nentyhj@mopipi.ub.bw
}

\section{Doi:10.5901/jesr.2015.v5n1p377}

\begin{abstract}
Poor interest and declining enrolment in agricultural education at senior secondary schools in Botswana has been a major concern which contradicts government policies of economic diversification through development in the agriculture sector. This study identifies factors underlying senior secondary school students' attitude towards agriculture and, based on these predicts students' willingness to enrol in the subject. Survey data was collected through the organisation of a validated Likert-type instrument from a multi-stage stratified random sample of 240 senior secondary students in Botswana. Principal components analysis and regression analysis were used for data analysis using SPSS 19 Software. Six attitudinal factors namely, attitude towards agriculture, willingness to study agriculture, usefulness of agriculture, value attached to agriculture, feelings towards agriculture and interest in agriculture were extracted. The derived scores for these factors significantly predict students' willingness to enrol in agriculture. The findings were discussed and it was recommended that the attitude of students towards agriculture should be improved by using encouragement and motivation strategies. Future research should include unseen or latent variables in the prediction of students' attitudes.
\end{abstract}

Keywords: Agricultural education, Likert scale, principal component analysis, derived factor scores, Regression analysis, enrolment in agriculture, factors underlying attitude

\section{Problem and Background of the Study}

Foster and Henson (1992) have stated that "agricultural sector is the foundation of any society" (p.79). The Government of Botswana has given priority to developing agriculture sector as one of the strategy to diversify the economy. Provision of agricultural education is one of the basic strategies for the development of agricultural sector in Botswana. In fact, Botswana need academicians and skilful people specialized in the field of agricultural science so as to support the motive of the Botswana government of improving the agricultural sector. Contradicting with government motive, majority of parents in Botswana do not want their children to be enrolled for agriculture. Students do not want to enrol for agriculture rather they would prefer to enrol for other optional subjects such as computer studies, business studies, art and design and technology (Lone, 2007). Students prefer other subjects as compare to agricultural science and therefore, students enroll in agricultural sciences only when they are unable to undertake alternative subjects or programs of study (FAO, 1997).

Despite the government's efforts to improve on agricultural sector in Botswana, the enrolment in agriculture at senior secondary schools has been declining. The parents and students are not willing to enrol in this subject which led to continuous decline in enrolment in agriculture. Agricultural education is not attracting as many students as other subjects resulting in declining enrollment in the agriculture subject as compared to total enrollment. The total enrolment of students in senior secondary schools in the country has increased by 56.59\% in 2009 compared to 2001 whereas enrolment in agriculture increased only by $1.23 \%$ (Botswana Educational Council, 2009). It clearly reflects that the trend in the enrolment in agriculture in senior secondary schools in Botswana has been poor in the past years.

Poor and declining enrolment trend in agriculture in senior secondary schools in Botswana is a major concern for agricultural educators across the country. The decline in enrolment and low interest towards agriculture in Botswana is unfavourable to the government efforts of improving agricultural sector. There can be many reasons for the decline in secondary agricultural enrolment. Lam (1987) identified interpersonal reasons, school factors, significant others, 
socioeconomic and home factors as barriers that influence students not to enrol in further educational pursuits. Kotrlik (1987) found that parents were the dominant influence on a student's decision whether to enrol in agriculture classes when attending high school. Students seek the advice of a teacher, parent, friend, counsellor and others before enrolling in agriculture. The attitudinal disposition towards agriculture among senior secondary students can be one of the factors which influence their willingness to enrol in the subject and therefore declining enrolment in agriculture. In order to improve recruitment, agricultural educators and policy makers need to understand what motivates and influence students to enrol in agricultural education (Herr, 1987). There has not been any prior research conducted on the attitudinal factors that influence students to enrol in agricultural science which studied the relationship between students' attitude towards agriculture and their willingness to enrol in the subject in Botswana. This study was an attempt to analyse factors underlying attitude of students towards agriculture and its influence on enrolment in the subject at senior secondary schools in Botswana

\subsection{Objectives and Research Questions of the Study}

The aim of the study was to predict senior secondary students' attitude towards agriculture and their willingness to enrol in the subject in Botswana. The specific objectives of this study were:

i) To identify the factors underlying senior secondary school students attitude towards agriculture.

ii) To predict the relationship between attitudinal factors of senior secondary students' and their willingness to enrol in the subject.

These objectives were translated into the following two research questions:

i) What are the factors underlying students' attitude towards agriculture?

ii) To what extent do the underlying factors of students' attitude towards agriculture predict their willingness to enrol in the subject?

\subsection{Statement of the Hypothesis}

While the first research question will be answered descriptively, the second research question will be answered by testing the following null hypothesis.

- The factors underlying attitude towards agriculture significantly predict students' willingness to enrol in agriculture.

\subsection{Significance of the Study}

One of the factors in the subject selection decision is attitude and its effect on interest in an agricultural education as well as agricultural career. For recruitment to be effective, it needs to be determined which factors have the greatest influence on the enrolment in agriculture. Policy makers need to have a good understanding of what underlying factors of attitude are influencing students to enrol if they are to increase and sustain enrolment in agricultural education. The study provided depth knowledge on factors underlying attitude and their relationship with the willingness to study agriculture. The study therefore would be able to assist all stakeholders, parents, teachers, administrators and policy makers to understand the role of students' attitude towards agriculture has on student willingness to enrol in the subject. This will eventually guide them in developing appropriate strategies to arouse the interest of the students in agriculture and therefore, improving the enrolment in agriculture.

\section{Theoretical Framework}

This study has its foundations in the work of Fishbein and Ajzen (1975) who determined that intentions to participate in an activity could be predicted based on knowledge, observation, or other information regarding a specific issue. Fishbein and Ajzen theorized that a person's beliefs, feelings, or intentions (attitude) towards an object can predict behaviour. The perceptions or beliefs and feelings towards agriculture can influence enrolment in agriculture (behaviour). In this study, students' willingness to enrol in agriculture may be predicted by analyzing their belief about agriculture and their experience. Greenwald (1989) supported this theory by reporting that individuals with positive attitudes toward a subject or situation tend to evaluate them positively and those with negative attitudes toward a subject or situation tend to evaluate them negatively. This theoretical structure or conceptual framework assumes a causal chain linking beliefs, 
formed on the basis of available information, to the person's attitude; beliefs and attitudes to intentions; and intentions to behaviours. It is necessary to distinguish among beliefs, attitudes, intentions, and behaviours and consider the relationships among the variables. In terms of the relationship between beliefs and attitudes, the conceptual framework suggests that a person's attitude toward some object is related to the set of his/her beliefs about that object, but not necessarily to a specific belief. Additionally, attitudes toward an object are viewed as being related to the person's intention to perform a variety of behaviours with respect to that object. Fishbein and Ajzen also indicated that ". . . attitude is viewed as one major determinant of the person's intention to perform the behaviour in question" (p. 16). As adapted to this research, the theory of attitude formation and change (Fishbein \& Ajzen,1975) suggests that students and parents, personal experiences, observations, knowledge and value about agriculture affect their attitude about agriculture, which in turn affects their belief, intentions and decision to participate (including enrolling for agricultural education). Thus, knowledge of students' attitude towards agriculture will, theoretically, provide an indication of their interest in pursuing agriculture as a field of their study.

The theoretical base of this study was reinforced by Aizen's and Fishbean's $(1975,1980)$ Theory of Reasoned Action and Ajzen's (1985) Theory of Planned Behaviour. According to Fishbein and Ajzen (1975), in general, an individual will hold a positive attitude toward a given behaviour if an individual believes that the performance of the behaviour will lead to mostly positive outcomes. On the other hand, if the individual believes that mostly negative outcome will result from the behaviour, and the individual will hold a negative attitude toward it. The theory suggests that a persons' intention is a function of two basic determinants. It Includes individuals' positive or negative attitude toward the behaviour and the subjective norm which relates to the social influence others have on the individual (Ajzen \& Fishbein, 1980). This also includes social dissuasion, the influence others have on discouraging an individual from choosing a particular behaviour (Richardson \& Watt, 2006). The theory of reasoned action can be used to predict, explain, and influence human behaviour (Ajzen \& Fishbein, 1980). Understanding a person's behaviour requires more than just knowledge of his/her intention, it also must include the ability to appropriately measure their intention by assessing beliefs and attitude in order to predict their behaviour (Fishbein \& Aizen, 1975). These theories served an instrument to explain how attitude are formed, and to understand the factor behind students' willingness to enrol in agriculture.

\section{Methodology}

\subsection{Research Design}

This quantitative study was designed to investigate and describe the attitude of the students towards agricultural education and its influence on the enrolment in agriculture by senior secondary school students in Botswana, thus making the study design an exploratory and descriptive in nature. According to Gray (2004) exploratory studies seek to examine what is happening and to ask questions about it. Not enough is known about attitudes of students towards agriculture and its relation to the willingness of students to enrol in the subject. Willingness to enrol in agriculture is dependent variable and the attitude towards agricultural education is the independent variable. Factors underlying students' attitude were treated as predictor to the students' willingness to enrol in agriculture.

The study used a descriptive survey method and designed a survey instrument that collected the information on the attitude of students and their willingness to enrol in agriculture. The survey was found the best method to explore the facts as the study was to explore the attitude of students because survey entails the hidden truth and facts about any social aspect and attitude is a social aspect (Babbie, 2007). This descriptive study was designed to obtain a complete and accurate description of a situation without showing a direct cause and effect relationship (Boyd, Westfall \& Stasch, 1981). Borg and Gall (1989) noted that the descriptive research method is used to describe, "What is." "Descriptive research studies are designed to obtain information concerning the current status of phenomena which direct the researchers toward determining the nature of the situation as it exists at the time of the study" (Ary, Jacobs, \& Razavich, 1990; p. 286).

\subsection{Instrumentation}

The data for the study were collected through administering a survey instrument designed after an extensive review of literature on attitude towards and willingness to enrol in agriculture. The first part of the instrument was designed to obtain demographic information about the students which included twelve variables. The second part of the instrument measured the students' willingness to enrol in agriculture. The Willingness to Enrol in Agriculture Scale (WEAS) 
instrument comprised of twelve items. The third section of the instrument measured the basic components of attitude was named as Agricultural Education Attitude Scale- AEAS and included three categories of thirty eight items: cognitive evaluation items (beliefs), affective evaluation items (feelings), and behavioural intention items (intentions). The items in the second and third section of the instrument were rated using a Likert scale (Likert, 1977) with four response options: Strongly Agree (SA), Agree (A), Disagree (D) and Strongly Disagree (SD) (Garland, 1991). Using an even number scale eliminated chances of neutral answers, which are reported in Oppenheim (1996) to be over-utilised by bored and reluctant questionnaire respondents.

\subsection{Validation and piloting of instrument}

Three agriculture teachers and a group of twelfth-grade students were asked some open-ended questions in order to capture a universe of attributes for the sake of investigating their attitudes towards agricultural education. Students' responses to the questions were analysed and then used as the main source in the construction of a large pool of instrument items. Then, the items were scrutinized, edited according to the rules of good attitudinal items established by Edwards (1983). Edwards suggested that statements be written in a clear, simple, and direct manner. This criterion was followed most easily by avoiding the use of compound, double-barrelled, or complex items. The next step involved was that a group of twelfth-grade students were asked to give their opinions for each item in terms of its relevance and clarity. In addition, one expert in the field of education and psychology was requested to review all the items in terms of their relevance and clarity as well. According to the students' judgments and experts' comments, scale items were modified and replaced. After this screening process, scale items were finalised for the instrument. The similar procedure was adopted to prepare the items for willingness to enrol instrument. A reliability coefficient was calculated to ensure the reliability of the instrument and the reliability estimate of both the scales gave a Cronbach alpha reliability coefficient for Agricultural Education Attitude Scale (AEAS) and Willingness to Enrol in Agriculture Scale (WEAS) to be .891 and .633, respectively showing a moderate to high level of consistency in measuring the two variables (Peterson, 1994).

\subsection{Data Collection}

The attitudinal disposition and willingness to enrol in agriculture may be influenced by the location of school and the gender of the respondents. Therefore, a multistage stratified random sampling was found appropriate (Borg \& Gall, 1989) and Krejcie and Morgan (1970). Four senior secondary schools out of a total of 30 government schools in Botswana; two schools from rural area and two schools from urban area; were selected randomly. A sample of 240 students composed of 120 students from agricultural education and 120 students doing non agricultural education were selected randomly.

The questionnaire was administered by the researchers themselves with the help of the teachers teaching the sampled students. After distribution of the questionnaire to the respondents in the class rooms, the respondents were explained what is expected of them to reduce error in providing information. The ethical code of conduct was duly followed for data collection.

\section{Data Analysis and Testing of Hypotheses}

\subsection{Research question}

"What are the factors underlying students' attitude towards agriculture?" Exploratory factor analysis was done to identify the factors underlying the students' attitude towards agriculture. The data were analyzed using factor analysis to reveal the latent factors behind students' attitude (Kim, 1985) and thus, the factors that influenced student's attitude towards agriculture were identified. Responses were subjected to a factor analysis using the Principal Component Analytical Approach (PCA) with varimax rotation method to extract the factors underlying students' attitude. The factor analysis was executed by using the SPSS 19 software package.

Only factors with eigenvalues equal to or greater than 1.0 were considered in the analysis. In addition, a scree plot of the eigenvalues was used to identify breaks or discontinuity in determining the number of factors. Based on Gorsuch (1983) recommendation to consider both the Kaiser-Guttman (Kaiser, 1970) criterion of retaining factors with eigenvalues greater than 1.0 and Cattell's (1966) scree test. An examination of the items in the factor loading pattern matrix was used to understand the nature of the extracted factors. These factor loadings indicated the correlation between each item and the derived factors. To assist in the interpretation and to reduce subjectivity, only items with factor loadings of .40 or 
higher were considered for labelling the factors.

\subsection{Testing of Null Hypothesis}

'The factors underlying attitude towards agriculture do not significantly predict students' willingness to enrol in agriculture". In order to answer second question and therefore to test this null hypothesis, the analysis was completed in two steps. First step, Pearson, Spearman, Kendall's rank correlation coefficient ( $r$ ) and means were calculated to determine relationships between the students' willingness to enrol and attitude toward agriculture. Davis (1971) measures of association were used to describe the correlation. Second step, multiple regression analysis was carried out to determine the extent the identified underlying factors of students' attitude predict their willingness to enrol in the subject. Willingness to enrol in agriculture and attitude towards agriculture were considered as the dependent variable and the independent variable, respectively.

\section{Results}

\subsection{Factors Underlying Student's Attitude towards Agriculture}

A Principal Component Analysis (PCA) was performed to extract the number of factors underlying students' attitude.

There were six independent patterns of relationship in the data and these may be thought of as evidencing six different kinds of influences on the data. This indicated that there were six categories by which these data may be classified; it illuminated six empirically different factors (components) describing the "student's attitudes towards agriculture". The Scree test was also performed to verify and support the results of the factorial solution.

Components with eigenvalues of 1 or higher (see Table 1)were the ones having the most effect on attitude of students towards agriculture and were included. Components with eigenvalues below 1 contributed very little to the explanation of the variance and were left out for further statistical analysis (Field, 2009). The results of the factor analysis have produced a six factor solution (Tables $1 \& 2$ ) which accounted for approximately 51.49 percent of the variance in the students' attitude towards agriculture education.

Table 1: Factor Matrix Loadings of the Students' Attitude towards Agriculture Items $(n=240)$

\begin{tabular}{|c|c|c|c|c|c|c|}
\hline \multirow{2}{*}{ Item } & \multicolumn{6}{|c|}{ Factor Loadings } \\
\hline & 1 & 2 & 3 & 4 & 5 & 6 \\
\hline I will not destroy my future by attending an agricultural school. & .624 & & & & & \\
\hline I like to study in an agricultural school. & .601 & -.337 & & & & \\
\hline I do not hate agricultural education. & .535 & -.386 & & & & \\
\hline I do not feel ashamed when I think of entering an agricultural school. & .512 & & & .322 & & \\
\hline Agricultural education gives me the opportunity to do the things I like to do. & .426 & .307 & -.333 & & & \\
\hline Agricultural education provides me with useful knowledge and skills. & .408 & & .408 & & & \\
\hline I like to spend my spare time doing manual work. & .404 & -.423 & & -.358 & & \\
\hline I do not feel shame while reading a book about agricultural education. & .396 & & & & & \\
\hline Agricultural education is not a total waste of time. & .396 & -.411 & -.309 & & .346 & .331 \\
\hline Agricultural education increases self confidence. & .386 & .301 & & & -.461 & .322 \\
\hline I like to spend my spare time reading books about agricultural education. & .384 & & & & & -.324 \\
\hline It is good for me to study in an agricultural school. & .381 & & & .405 & & \\
\hline I do not have negative feelings toward agricultural education. & .369 & & .369 & & .444 & \\
\hline I like to read agricultural education books. & .368 & .431 & & & & -.462 \\
\hline Agricultural education is useful to the society. & .358 & .319 & .327 & -.311 & & \\
\hline I feel happy when I discuss any topic about agriculture. & .358 & .336 & & & .311 & .343 \\
\hline Agricultural education must not be eliminated from our schools. & .324 & & & .529 & -.318 & \\
\hline Agricultural education is useful. & .330 & & .447 & & .361 & \\
\hline$\%$ of Variance accounted for by each factor & 18.38 & 7.83 & 6.99 & 6.39 & 6.14 & 5.75 \\
\hline
\end{tabular}

Table 1 provides a matrix of item loadings of the students' attitude towards agriculture $(n=240)$. It indicates each component and how much they contributed to the total variance in the students' attitude towards agriculture. Total variance explained was expressed in eigenvalues. 
The first three components accounted for much of the total variance explained (33.21\%). Six factors extracted from the content of the 18 items were labelled with suitable names in order to identify the factors. For the purpose of the interpretation and to reduce subjectivity, only items with factor loadings of .3 or higher were considered for labelling (naming) the factors. The six extracted factors were labelled as (1) Attitude towards agriculture, (2) willingness to study agriculture, (3) Usefulness of agriculture, (4) Value attached to Agriculture, (5) Feelings towards agriculture, and (6) Interest in agriculture.

Table 2: Eigenvalues and Percent of Variance Explained by six attitudinal factors towards agriculture $(n=240)$

\begin{tabular}{llll}
\hline Factor & Eigenvalue & $\%$ of variance & Cumulative \% of variance \\
\hline Attitude towards agriculture & 3.309 & 18.38 & 18.38 \\
Willingness to study agriculture & 1.410 & 7.83 & 26.21 \\
Usefulness of agriculture & 1.259 & 6.99 & 33.21 \\
Value attached to agriculture & 1.151 & 6.39 & 39.60 \\
Feelings towards agriculture & 1.105 & 6.14 & 45.74 \\
Interest in agriculture & 1.035 & 5.75 & 51.49 \\
\hline
\end{tabular}

Figure 1 indicates that the 18-item attitude scale is a multidimensional scale with six underlying factors. Therefore, all the 18 items should not be combined to create one single factor. Instead, items should be distributed on the six factors. It is clear from scree plot that only six factors can be extracted from 18 components before the curve becomes straight. It is also clear that only six factors have eigenvalues greater than one, which is the main criterion for defining and selecting the number of factors in the factorial solution.

\subsection{Prediction of Students' Willingness to Enrol in Agriculture}

The multiple regression analysis was used to predict the differences in students' attitudes on the attitude scale. The six extracted underlying attitudinal factors were considered as independent variables and the scores of willingness to enrol in agriculture were as the dependent variable. Tables 2 represented the multiple regression analyses and the relative importance of the independent variables to explain the variance to the attitude. From the Table 2, it is clear that the pvalue $(<.001)$ corresponding to the F value (12.82) is smaller than a $(.05)$ and therefore the null hypothesis is rejected. There is significant influence of the six factors underlying attitude on the students' willingness to enrol in agriculture and therefore, the six attitudinal factors are significant predictors of the students' willingness to enrol in agriculture education.

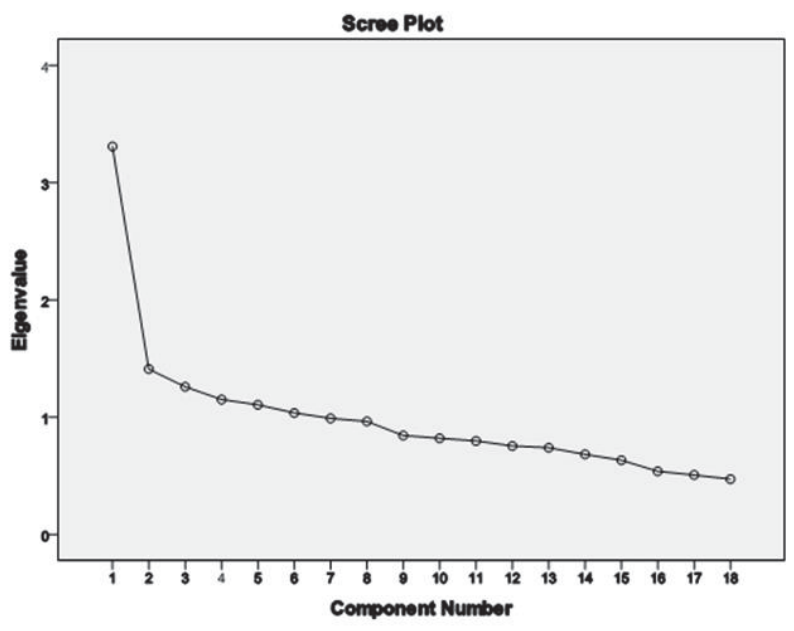

Figure 1: Scree test from a principal component analysis of 18 item variables showing one dominant factor and five secondary factors 
Table 2: Regression Analysis of the Influence of Attitude towards Agriculture on Willingness of Students to Enrol in Agriculture

\begin{tabular}{|c|c|c|c|c|c|}
\hline Source & SS & $\mathrm{df}$ & & $\mathrm{F}$ & $\mathrm{p}<$ \\
\hline Regression & 826.946 & 6 & & 12.819 & .001 \\
\hline Residual & 2505.054 & 233 & & & \\
\hline Total & 3332.000 & 239 & & & \\
\hline \multicolumn{3}{|c|}{$\begin{array}{l}\text { Independent variables } \\
\text { (Factor scores from attitude items) }\end{array}$} & Beta & $\mathrm{t}$ value & Sig. \\
\hline \multicolumn{3}{|c|}{ Constant } & -- & 137.017 & 0.000 \\
\hline \multicolumn{3}{|c|}{ Attitude towards agriculture (ATA) } & 0.483 & 8.499 & 0.000 \\
\hline \multicolumn{3}{|c|}{ Willingness to study agriculture (WSA) } & 0.046 & 0.812 & 0.418 \\
\hline \multicolumn{3}{|c|}{ Usefulness of agriculture (UA) } & -.104 & -1.822 & 0.070 \\
\hline \multicolumn{3}{|c|}{ Value attached to agriculture (VAA) } & 0.000 & -0.002 & 0.998 \\
\hline \multicolumn{3}{|c|}{ Feelings towards agriculture (FTA) } & 0.030 & 0.523 & 0.602 \\
\hline \multicolumn{3}{|c|}{ Interest in agriculture (IA) } & 0.037 & 0.655 & 0.513 \\
\hline
\end{tabular}

Multiple $\mathrm{R}=.498 ; \mathrm{R}$-square $=.248$

$Z_{\text {WTEA }}=.48 Z_{\text {ATA }}+.05 Z_{W S A}-.10 Z_{U A}+.00 Z_{U A A}+.03 Z_{F T A}+.04 Z_{I A}$

Results of multiple regression analysis have indicated that all the six extracted attitudinal factors taken together are statistically significant $(F=12.82, \mathrm{df}=6,233$, Sig. $=<.001)$ predictors of students' willingness to enrol in agriculture (Table 2). The total variance of willingness to enrol in agriculture explained by this regression model was 24.8 percent. According to beta values all the factors except Factor 3 (usefulness of agriculture) are positively regressed on the students' willingness to enrol in agriculture. The rank order of the variables indicates that the Factor 1 (attitude towards agriculture) is the most important attitudinal factor which is highly significant $(p<.001)$ factor in the predictor of students' willingness to enrol in agricultural education.

\section{Discussion}

\subsection{Factors Underlying Student's Attitude towards Agriculture}

The principal component analysis produced six factors underlying students' attitude towards agriculture and were labelled as attitude towards agriculture, willingness to enrol in agriculture, usefulness of agriculture, value attached to agriculture, feelings towards agriculture and, interest in agriculture. The first factor was the most important one since it accounted for $18.38 \%$ of the total Agricultural Education Attitude Scale (AEAS) variance. This factor was labelled as 'attitude towards agriculture' because it included all items describing general attitude of students towards agriculture which included items reflecting negative as well as positive attitude towards agriculture. The two items with the highest loading on this factor were 'I will destroy my future by attending an agricultural school' and 'I do not like to study in an agricultural school'. These two items, however reflects negative attitude of students towards agriculture but there are other items which reflects positive attitude also such as Agricultural education gives me opportunity to do things I like to do and Agricultural education increases self confidence. Therefore, this factors was named 'attitude of agriculture' because it contained items reflecting positive and negative attitude towards agriculture.

The second factor accounted for $7.83 \%$ of the variance and was labelled as 'willingness to study agriculture'. The two items with the highest loadings on this factor were those of 'I like to read agricultural education books' and 'I like to spend my spare time doing manual work'. The third factor accounted for $6.99 \%$ of the variance, and consisted of items referring to the use of agriculture in the life, and was therefore called 'usefulness of agriculture'. This usefulness is interpreted as the perception that students have in terms of how agriculture will be useful and help them as well as the society. The two items with the highest loading on this factor were 'agricultural education is useless' and 'Agricultural education provides me with useful knowledge and skills'. The fourth factor accounted for $6.39 \%$ of the variance and was labelled as 'value attached to agriculture'. The two items with the highest loading on this factor were 'Agricultural education must be eliminated from our school' and 'It is good for me to study in an agricultural school'.

The fifth factor accounted for $6.14 \%$ of the variance and was incorporating items related to feelings of the students towards agriculture and therefore was named as 'feelings towards agriculture'. The two items with the highest loading on this factor were 'Agricultural education increases self confidence' and 'I have negative feeling towards agricultural education'. The last and the sixth factor accounted for $5.75 \%$ of the total variance to the total attitudinal factors. This 
factor was named 'interest in agriculture'. All the items loaded on this factor are also loaded significantly on factor 1 (attitude towards agriculture). Hence, this factor was named as interest in agriculture which is a component of attitude towards agriculture. These two items with highest loading on this factor were 'I like to read agricultural education books' and 'I feel happy when I discuss any topic about agriculture'.

However, the six factors identified have contributed a variability of $51.49 \%$ to the attitude of students. On the one hand, it indicates that these six factors are important in formation of the attitude of students. On the other hand, it also reflects that there are still some latent factors underlying students' attitude towards agriculture which contribute to the remaining $48.51 \%$ variance to the students' attitude towards agriculture. The underlying attitudinal factors were named comprising the words attitude, willingness, usefulness value, feelings and interest. These key words are also components of attitude which justify the tripartite theory of attitude as the theoretical framework of the study is based.

\subsection{Prediction of Students' Willingness to Enrol in Agriculture}

Results of regression have clearly showed that one of the six of the attitudinal factors is significant predictor of students' willingness to enrol in agriculture. This factor, which attracted significant loadings from all the items (Table 1), could be said to constitute a common factor, which is the main attitudinal factor. These results are important and meaningful in the sense that the identified factors are significant predictors of students' behaviour to choose agriculture, in addition to their attitudes. Still, the multiple regression model of all the factors explained only 24.8 percent of the variance in students' attitude. This result indicates the importance of latent variables for explaining a large portion of students' attitude, which might make the prediction of human behaviour even more complex in actual situations, and this explains the weak relationship between attitudes and behaviour (Schwarz, 2001).

The significant relation between students' attitudes and their willingness to enrol in agriculture (behaviour) demonstrated by this study means that students' behaviour to choose or enrol in agricultural education is determined by their feeling about or attitude towards agriculture itself reflects higher attitude scores on the attitude continuum. This result is consistent with the overall conclusion, in the literature, that attitudes are assumed to be predictive of human behaviour (Summers, 1977). Social psychologists (Ajzen, 2002) have been enthusiastically motivated to provide empirical findings to support their presumptions of a strong theoretical relationship between attitudes and behaviour. Their motivation is simply based on the principle that an individual's attitude towards some object may be inferred from his or her behaviour towards the attitude object. Unfortunately, however, individuals' behaviour is influenced by many variables other than their attitude.

Ajzen and Fishbein (2000), in their review of the influence of attitudes on behaviour, indicated that initial reactions focused on the validity of the attitude measure, suggesting either that responses to standard attitude scales were contaminated by social desirability bias and hence failed to capture true attitudes, or that these measures provided an incomplete assessment of the attitude construct. They concluded that "variables in addition to attitude must be taken into consideration, suggesting that attitudes play a very limited role because they are important predictors of behaviour only for certain individuals and in certain situations" (p.182). Student's behaviour is also explained by other variables depending on the context of the situation. The results of logistic regression have confirmed and supported the conclusion in the literature that attitudes are not the only predictors of human behaviour.

It is true that human behaviour is complex and therefore very difficult to explain and predict. Investigators proposed that general attitudes can have a strong impact on behaviour, but that is to be expected only under certain conditions or for certain types of individuals (Ajzen \& Fishbein, 2000). The conclusion from this discussion indicates that attitudes are only one part of the pool of factors that may influence behaviour, and even this influence is situationspecific. The complexity of predicting actual behaviour from attitudes is well established in the literature. Social psychologists' contention that attitudes should predict actual behaviour, is quite logical and consistent at the theoretical level, but at the measurement level the situation is different and the prediction is not straightforward. This indicates the interdependence between attitude theory and measurement of attitude. Valid and reliable measurement of attitudes provides insights into the theoretical model of the attitude-behaviour relationship.

\section{Conclusion}

Factor analysis extracted six underlying factors accounted for 51.49 percent of the variance in the attitudes of students has toward agriculture. The Six attitudinal factors were named as (1) Attitude towards agriculture, (2) willingness to study agriculture, (3) Usefulness of agriculture, (4) Value attached to Agriculture, (5) Feelings towards agriculture, and (6) 
Interest in agriculture. Based on the percent variance of the six identified attitudinal factors, it can also be concluded that there are still latent factors contributing to the remaining variance (48.51\%) to the attitude. The six attitudinal factors underlying students' attitude towards agriculture are the components of repatriate theory of attitude which formed the theoretical framework of this study. Therefore, the finding of this study support the attitude theory adopted for this study.

Regression analysis has indicated that the extracted attitudinal factors are significant predictors of students' willingness to enrol in agriculture. Therefore, it is important to improve on the students attitude towards agriculture if the enrolment in agriculture to be improved in Botswana.

\section{Recommendations}

Improvement in human survival depends on the improvement in agriculture for successful accommodation of increasing population worldwide and therefore, agricultural education is important. The declining enrolment in the subject has been a barrier to improve education and skills in agriculture in Botswana. This problem cannot be tackled, unless the prevailing (negative) attitude of students' towards agriculture is reversed. There is a need to look into the factors contributing to the prevailing (negative) attitude towards agriculture and formulate effective policies to minimize such factors.

Professionals, especially teachers should encourage and motivate students by raising the awareness among students about careers and opportunities in agriculture sector. The government should put efforts to promote awareness on the importance of agriculture and career development in agriculture, not only among students but also parents, in order to change their current mindset and attitude towards agriculture. It is important that the community and especially the potential students should be make aware of the career development and employment opportunities, possibly by organising field trips, summer internships, road shows, broadcasting of audio and video programs, exhibitions or school visits by the agricultural agencies and circulation of brochures.

The Ministry of Education and school administrators should give full support and promote this subject rather than considering it as the least important subject in schools. Attractive financial packages and incentives can be offered to students who exemplify good academics and skills in the field of agriculture. Government may explore the possibility of making agriculture a compulsory subject for all the senior secondary students in Botswana which might help in creating interest in agriculture, increasing the willingness to enrol in the subject.

Similar research can be undertaken using mixed methods research design so as to have deep knowledge on the students' attitude towards agriculture and their willingness to enrol in agriculture Further investigation of unseen or latent factors accounting for additional variance in the students' attitudes towards agriculture needs to be undertaken.

\section{References}

Ajzen, I. (2001). Nature and operation of attitudes. Annual Review of Psychology, 52, 27-58.

Ajzen, I., \& Fishbein, M. (2000). Attitudes and the attitude-behaviour relation: Reasoned and automatic processes, In W. Stroebe \& M. Hewstone (Eds.), European Review of Social Psychology (pp. 1-33). Chichester, England: John Wiley \& Sons.

Ary, D., Jacobs, L.C., \& Razavieh, A. (1996). Introduction to research education (5th ed.). Fort Worth: Liarcourt Brace College Publishers.

Babbie, E. (2007). The practice of social research (11 th ed.). Singapore: Thomson Wadworth.

Borg, W. R., \& Gall, M. D. (1983). Educational research: An introduction. New York: Longman.

Botswana Educational Council (2009). BGCSE examination summary of results. Gaborone: Government Printer.

Cattell, R. B. (1966). The scree test for the number of factors. Multivariate Behavioural Research, 1, 245.

Cronbach, L. (1951). Coefficient alpha and the internal structure of tests. Psychometrica, 16 (3), 297-334.

Davis, J.A. (1971). Elementary survey analysis. Englewood Cliffs, NJ: Prentice-

Edwards, A.L. (1983). Techniques of attitude scale construction. New York: Irvington Publishers.

Edwards, A., \& Kilpatrick, F. (1977). A technique for the construction of attitude scales. In G.F. Summers (Ed.), Attitude measurement (pp.214-221).London: Kershaw Publishing Company.

Fabrigar L.R., MacDonald T.K., \& Wegener D.T. (2005). The structure of attitudes. In D. Albarracin, B.T. Johnson, \& M.P. Zanna (Eds.), The handbook of attitudes (pp.79-103). Mahwah, NJ: Lawrence Erlbaum Associates.

Field, A. (2009). Discovering statistics using SPSS (3 ${ }^{\text {rd }}$ ed). Sage Publications: London.

Fishbein, M., \& Ajzen, I. (1975). Beliefs, attitude, intentions and behaviours readings,MA: Addison-Wesley Publishing Company.

Foster, E., \& Henson, W. (1992). MANRRS: The National Society for Minorities in Agriculture, National Resources and Related Science, 1986-92. Agriculture and Human Values, 9 (1), 79-81

Gorsuch, R. L. (1983). Factor analysis. (2nd ed.). Hillsdale, NJ: Lawrence Erlbaum.

Greenwald, A. G. (1989). Why attitudes are important: Defining attitude and attitude theory 20 years later. In A. R. Pratkanis, S. J., Breckler, \& A. G. Greenwald (eds.), Attitude structure and function (pp.429-440). Hillsdale, NJ: Lawrence Erlbaum Associates. 
Herr, E. L. (1987). National allies. Vocational Education Journal, 55 (6), 30-33.

Kaiser, H. F. (1970). A second generation Little Jiffy. Psychometrika, 35, 401-415.

Kim, J. (1985). Factor Analysis: Statistical Package for the Social Sciences. Nie, N., Hull, C., Jenkins, J., Steinbrenner, K., \& Bent, D. (Eds.) McGraw Hill Book Co., New York.

Kotrlik, J. W. (1987). Factors related to the career decisions of seniors who have taken vocational agriculture. The Journal of American Association of Teacher Educators in Agriculture, 4, 250-56.

Krejcie, R.V., \& Morgan, D.W. (1970). Determining sample size for research activities. Educational and Psychological Measurements, $30,607-610$

Lam, J. Y. (1987). Determinants of educational plans of the indeterminate high school graduate. The Journal of Educational Administration, 20 (2), 13-229.

Likert, R. (1977). A technique for the measurement of attitudes. In G.F. Summers (Ed.), Attitude measurement (pp.149-158). London: Kershaw Publishing Company.

Lone, M. (2007). Student's attitude towards agriculture at Maikano Community Junior Secondary School. The Entrepreneur, CEDA Newsletter, 18-19.

Oppenheim, A.N. (1996). Questionnaire design, interviewing and attitude measurement. London and New York: Continuum.

Peterson, R.A. (1994). A meta-analysis of Cronbach's Coefficient Alpha. Journal of Consumer Research, 21, 34-47.

Summers, G. F. (1977). Introduction. In G. F. Summers (Ed.), Attitude measurement (pp.1-17). London: Kershaw Publishing Company. 
